\title{
A review of neurophysiological testing
}

\author{
RichaRd M. LehMAN, M.D. \\ Department of Surgery, Division of Neurosurgery, Robert Wood Johnson Medical School, University \\ of Medicine and Dentistry of New Jersey, New Brunswick, New Jersey
}

\begin{abstract}
The rapid advances in the technology of, and accumulation of pertinent data in, electrophysiological testing has increased exponentially in the past decade. This is attributable to continued advances in computer technology, biomedical engineering, and now the coregistration of the electrophysiological data with neuroimaging results. Knowledge of normal function and electrophysiological response at rest or on stimulation of the central and peripheral nervous systems is important to the neurosurgeon. Only by a basic understanding of normal and abnormal recordings may diagnoses and localizations be achieved. Intraspinal and intracranial surgical procedures are predicated on nontrauma to the neuraxis. This can be accomplished by performing electrophysiological testing to monitor the function of the spinal and cranial nerves, spinal cord, brainstem, basal ganglia, and cerebrum. If the surgeon cannot delineate critical cortex or pathways, he or she will be unable to avoid these areas in the patient.
\end{abstract}

\author{
KEY WORDS • electrophysiological testing • electroencephalography • \\ magnetoencephalograpy - evoked potential - computerized tomography imaging • \\ motor pathway stimulation
}

Sophisticated electrophysiological testing is available to the neurosurgeon for diagnosis and localization. It is imperative that he or she has a basic understanding of neurophysiology and clinical testing of the nervous system as well as recent advances in the field. The purpose of this paper is to review the field of electrophysiological testing and to present the information to the reader in a clear and practical fashion. Recent advances including MEG and functional imaging are presented.

This review is divided into several sections: electromyography and nerve conduction, EEG, MEG, evoked response monitoring, intraoperative testing (including cranial nerve monitoring, basal ganglia and thalamic localization with microelectrode recordings, and cortical mapping), and an overview of neurophysiological testing to help the surgeon protect the spinal cord.

Abbreviations used in this paper: $\mathrm{BAEP}=$ brainstem auditory evoked potential; CMAP = compound muscle action potential; $\mathrm{CNS}=$ central nervous system; CT = computerized tomography; $\mathrm{ECoG}=$ electrocorticography; $\mathrm{EEG}=$ electroencephalography; $\mathrm{EMG}=$ electromyography; $\mathrm{MAP}=$ muscle action potential; $\mathrm{MEG}=$ magnetoen- cephalography; $\mathrm{MR}=$ magnetic resonance; PLED = periodic lateralized epileptiform discharge; $\mathrm{SD}=$ standard deviation; SSEP = somatosensory evoked potential; STN = subthalamic nucleus; Vim = nucleus ventralis intermedius.

\section{ELECTROMYOGRAPHY AND NERVE CONDUCTION STUDIES}

A variety of techniques are available for the electrodiagnosis of the pathologies of muscle, peripheral nerve, and their CNS distribution. Historically, the earliest investigations were performed in the latter portion of the 18th century by Galvani, who published his observations on electricity and muscle contraction. In 1848 Dubois-Raymond discovered the action potential and described it as a negative variation of the standing potential of a nerve related to the conduction of a nerve impulse. Soon thereafter, Hermann von Helmholtz recorded the conduction velocity in a median nerve in a human. ${ }^{129}$

\section{Anatomy and Physiology}

The peripheral nerve trunk contains motor, sensory, and autonomic axons, which may be myelinated or unmyelinated; the latter ones have a slower conduction velocity. The resting transmembrane potential of an axon is -80 to $-90 \mathrm{mV}$, based on a membrane impermeable to $\mathrm{Na}^{+}$ on the outside but permeable to $\mathrm{K}^{+}$intracellularly. ${ }^{119} \mathrm{Al}$ though the ionic concentrations are equal on either side of the membrane, there are higher concentrations of $\mathrm{K}^{+}$on the inside and $\mathrm{Na}^{+}$on the outside of the membrane. These 
concentrations are maintained by the transmembrane potential and the active transport of $\mathrm{Na}$ and $\mathrm{K}$ by an energydependent pump. ${ }^{109}$ When a stimulus is introduced to the axonal membrane, permeability to $\mathrm{Na}^{+}$increases. This brings about a transient change in the transmembrane potential, which increases the conductance of $\mathrm{Na}^{+}$into the cell until the $\mathrm{Na}^{+}$equilibrium potential is reached (30 $\mathrm{mV}$ ). Once started, the change is rapidly propagated to adjacent inactive portions of the membrane. The propagated disturbance is known as an impulse and the electrical manifestation as the action potential. The creation of this local flow of electrical charge reduces the membrane potential in the inactive regions, increasing permeability of $\mathrm{Na}^{+}$and the flow of current proceeds in continuity. As the initial area repolarizes with $\mathrm{Na}^{+}$, conductance low and $\mathrm{K}^{+}$increasing, this process is repeated successfully in both directions from the point of stimulation at a constant velocity and duration, depending on the nerve fibers' excitability and conductive properties. ${ }^{129}$

Conduction has two types: continuous or saltatory. The former occurs in unmyelinated nerve fibers and is continuous and bidirectional. Conduction in a myelinated fiber occurs in a somewhat different manner, however. The myelin sheath, an effective insulator, is covered by a Schwann cell. The cell process is interrupted at intervals up to $2 \mathrm{~mm}$ along the length of the fiber, and the axon is uncovered. This is the node of Ranvier. The circuit flow is also bidirectional from one node of Ranvier to the next. The impulse hops from one node to the next (saltatory), resulting in faster conduction. Therefore, large-diameter fibers have faster conduction times (Table 1). ${ }^{70}$

When a mixed nerve is maximally stimulated and recorded monophasically, there is a somewhat irregular contour to the action potential based on the different velocities and thresholds of the nerve (this is called a "compound nerve action potential"). Following the fall of the electri-

TABLE 1

Types of nerve fibers

\begin{tabular}{lc}
\hline \hline \multicolumn{1}{c}{ Fiber Type \& Diameter } & Conduction Speed $(\mathrm{m} / \mathrm{sec})$ \\
\hline A fibers: myelinated fibers of somatic & $5-120$ \\
nerves & \\
muscle nerve & \\
afferent group & \\
I $(12-21 \mu)$ & \\
II $(6-12 \mu)$ & \\
III $(1-6 \mu)$ & \\
IV $(C$ fiber $)$ & \\
efferent group & \\
$\alpha$ motor neuron & \\
$\gamma$ motor neuron & \\
cutaneous nerve & \\
afferent group & \\
$\quad \alpha(6-17 \mu)$ & $3-15$ \\
$\gamma(1-6 \mu)$ & \\
B fibers: myelinated preganglionic fibers & \\
of autonomic nerve & \\
C fibers: unmyelinated fibers of & \\
somatic or autonomic nerve & \\
sC fibers: efferent postganglionic fibers & \\
of autonomic nerve & \\
drC fibers: afferent fibers of the dorsal & \\
root \& peripheral nerve &
\end{tabular}

cal response in the action potential, there are two lowamplitude, relatively low deflections, based on prior spike activity. The first is a negative after-potential. The nerve is still excitable at this point, and, in fact, may be more easily excitable. Following this, a positive after-potential occurs where the nerve has a high threshold to activation. Both states relate to $\mathrm{Na}^{+}$permeability. ${ }^{39}$

A motor unit consists of a motor axon and the population of muscle fibers innervated. ${ }^{79}$ The neuromuscular junction is a synapse at which the neural impulse stimulates the release of acetylcholine from the axon terminals, resulting in a brief muscle contraction. The consequent electrical response is the CMAP. ${ }^{6}$ There is release of $\mathrm{Ca}$ from the vesicles of the sarcoplasmic reticulum, which facilitates the cross bridging between myosin and actin filament of the myofibrils in the presence of adenosine $5^{\prime}$ triphosphate, resulting in shortening of the muscle. ${ }^{155}$

Muscle, as opposed to nerve, may have a heightened response on increased frequency of nerve stimulation. This is called "summation," which may lead to sustained contraction (tetanus). Skeletal muscle may only be activated by motor neurons as opposed to cardiac or smooth muscles. ${ }^{155}$ Fast-fatigue and fast-resistant motor units, innervated by large-diameter nerves, are present in the more anaerobically functional muscles. The slow motor unit with smaller-diameter neurons innervate the more aerobically functional muscle fibers. ${ }^{27}$ When contraction of the muscle occurs, there may be shortening (isotonic), no shortening or external work (isometric), or lengthening when the external force is greater than the muscle contraction. ${ }^{155}$

\section{Pathological Features and Testing}

Pathological Features. Seddon ${ }^{127}$ described three forms of nerve injury: neurapraxia, axonotmesis, and neurotmesis. In neurapraxia, there is conduction loss without structural change of the axon, and recovery takes place within days or weeks. The conduction velocity, if initially slowed, is probably due to focal demyelination, but should return to normal with remyelination. In chronic entrapment, focal demyelination is due to mechanical forces, but there can be axonal damage. During a complete block, stimulation below the nerve reveals normal excitability. The degree of compression determines the severity of the conduction block, but not the recovery rate..$^{55}$

Axonotmesis results in axonal damage and loss of continuity with wallerian degeneration of the distal segment, followed by denervation-induced muscle atrophy. ${ }^{86}$ Distal excitability is lost in 4 or 5 days, first at the neuromuscular junction and then at the distal nerve segment ${ }^{86}$ Regeneration occurs slowly at 1 to $3 \mathrm{~mm}$ per day. ${ }^{19}$

Neurotmesis occurs when the nerve is disrupted. This may happen in varying degrees where perineurium is preserved, but axons and supportive tissue are disrupted nonetheless. Regeneration results in a very poor return of continuity and requires surgical repair. Despite microsurgical repair, functional recovery remains poor based on the axon's ability to select the appropriate target to reinnervate. ${ }^{91,137}$ Conduction velocity may reach $60 \%$ in 4 years. ${ }^{54}$ Persistent prolongation of distal latencies indicates a limited number of fibers distally reaching the appropriate target. 
Testing. The laboratory testing in a patient involves the needle electrode examination and recording of muscles at rest and with varying degrees of voluntary contraction. Nerve conduction studies are performed at the same time and coordinated with the clinical examination.

The EMG study conducted while a patient is at rest reveals no spontaneous activity except for insertional activity from placement of needle electrodes, which may be monopolar or bipolar. Insertional activity may become prominent in denervation or acute myopathies. Fibrillation potentials are the action potentials of single muscle fibers and occur when the motor axon has been interrupted. They are biphasic or triphasic with initial positive defection. Their duration is 1 to $5 \mathrm{msec}$ and their amplitude varies from 30 to $50 \mu \mathrm{V}$. There may also be associated sharp waves. These potentials appear in 2 to 4 weeks. In contrast, fasciculation potentials are polyphasic and associated with denervation caused by varying degrees of severity of pathological features, but involve a visible muscle twitch. These twitches originate from motor units. Myotonic discharges are trains of single muscle fiber action potentials. ${ }^{27}$ Their duration is long and the amplitude and frequency may vary. ${ }^{54}$

Abnormal results on EMG and the degree of denervation are reflected by the amount of spontaneous neurotonic activity. Hence, spontaneous muscle activity is a reflection of the degree of axonal loss. Additionally, voluntary contraction and recruitment of motor units assess denervation and reinnervation..$^{27}$

\section{Nerve Conduction Studies}

Nerve stimulation is performed using surface electrodes, usually made of silver plate (Fig. 1). The stimulating electrodes consist of cathode and an anode. The current flows between the two, and depolarization of the nerve occurs at the cathode, which should be placed closest to the recording site. Some physicians prefer a monopolar electrode as a subcutaneous needle electrode. Stimulation may be constant-voltage, in which the voltage is regulated and the current varies inversely to the impedance, or constant-current in which voltage varies according to impedance but a chosen current reaches the nerve. ${ }^{70}$ Nerves may be stimulated antidromically or orthodromically (Fig. 2).

Stimulus pulses are of square-wave and variable duration. Intensity varies from 10 to $30 \mathrm{~mA}(100-300 \mathrm{~V})$ and 0.05 to $2 \mathrm{msec}$ duration. Diseased nerves may require longer duration pulse widths and up to 40 to $50 \mathrm{~mA}$ $(400-500 \mathrm{~V})$ stimulation intensity. Surface electrodes are generally used for recording both the nerve action potential and the compound MAP, generated by stimulating the motor axons. These are averaged, amplified, and displayed by using an oscilloscope with computer storage of data and retrieval. ${ }^{129}$

The motor nerve conduction time equals the latency minus the time for nerve activation, neuromuscular transmission, and MAP. Conduction velocity $(\mathrm{m} / \mathrm{sec})$ is expressed by the formula distance between stimulation points/latency (proximal) - latency (distal) (Fig. 3). ${ }^{70}$ This is performed by stimulating at different points along the nerve.

Sensory nerve fibers may be stimulated orthodromical-
TABLE 2

Sensory nerve conduction studies commonly available in the EMG laboratory*

\begin{tabular}{llllll}
\hline \hline & & & & \multicolumn{2}{c}{ Normal Values $\dagger$} \\
\cline { 3 - 6 } \multicolumn{1}{c}{ Nerve } & $\begin{array}{c}\text { Stimulation } \\
\text { Site }\end{array}$ & \multicolumn{1}{c}{$\begin{array}{c}\text { Recording } \\
\text { Site }\end{array}$} & AMP & DL & CV \\
\hline $\begin{array}{l}\text { median } \\
\text { ulnar }\end{array}$ & $\begin{array}{l}\text { wrist } \\
\text { urist }\end{array}$ & $\begin{array}{l}\text { fingers 1, 2, \& } 3 \\
\text { finger 5 }\end{array}$ & $>20.0$ & $<3.3$ & $>50.0$ \\
ulnar & forearm & dorsum, hand & $>18.0$ & $<3.0$ & $>50.0$ \\
radial & forearm & dorsum, hand & $>18.0$ & $<3.0$ & NA \\
lateral antebrachial & elbow & forearm & $>16.0$ & $<2.9$ & NA \\
cutaneous & & & & & \\
sural & calf & lateral malleolus & $>6.0$ & $<4.4$ & NA \\
superficial peroneal & shin & lateral malleolus & $>6.0$ & $<4.4$ & NA \\
saphenous & shin & medial malleolus & $>6.0$ & $<4.4$ & NA \\
\hline
\end{tabular}

* Reprinted with permission from Youmans JR (ed): Neurological Surgery, ed 3. Philadelphia: WB Saunders, 1990. AMP = amplitude $(\mu \mathrm{V})$; $\mathrm{CV}=$ conduction velocity $(\mathrm{m} / \mathrm{sec}) ; \mathrm{DL}=$ distal latency $(\mathrm{msec}) ; \mathrm{NA}=$ not applicable.

$\uparrow$ Normal values are for young adults and vary from laboratory to laboratory. Some normal values in this table are obtained courtesy of the EMG laboratory, The Cleveland Clinic.

ly or antidromically and require amplification two orders of magnitude $\left(10^{2}\right)$ greater than that of motor axons. Sensory latency consists of only the nerve activation and conduction time to the recording electrode. Sensory fibers with large diameters have lower thresholds and conduct faster than most motor fibers (Table 2). ${ }^{70}$

Late responses (that is, latency responses longer than the initial muscle responses) may be recorded by stimulating a mixed nerve with large afferent fibers and recording in the muscle to receive the efferent response. This requires a low intensity stimulus and is called the H-reflex. It requires the monosynaptic reflex to be intact. This is commonly measured in the lower extremity by using the tibial nerve and recording in the soleus muscle. A stronger stimulus will antidromically stimulate the motor axons with a return volley to the muscle. This is the F-response (Fig. 4). ${ }^{129}$

Abnormalities of motor nerve conduction when stimulating between two points are of three types: 1) reduced amplitude with normal to slightly prolonged latency; 2) increased latency with normal amplitude; and 3) absent response. In general, axonal dysfunction results in a reduction in amplitude and demyelination leads to prolonged conduction time. ${ }^{70}$ The distinction between acute partial neurapraxia and early axonotmesis is revealed by a loss of response when stimulating the nerve below a lesion 4 to 5 days later. At this time, the distal axons have lost excitability in the latter type of disease (Table 3).

Entrapment syndromes of the upper extremity most commonly involve median nerve compression at the carpal ligament. There have been findings of prolonged distal motor latency to the abductor pollicis brevis muscle, as well as sensory abnormalities ranging from prolonged latencies to loss of amplitude on stimulation with a ring electrode on the index finger. Differences in peak latencies of $0.4 \mathrm{msec}$ or more are considered abnormal. ${ }^{60}$ The pronator syndrome occurs when the median nerve is compressed between the two heads of the pronator teres muscle. Motor and sensory testing may not always be helpful, but EMG studies may show denervation of abductor pol- 
TABLE 3

Motor nerve conduction studies commonly available in the EMG laboratory*

\begin{tabular}{|c|c|c|c|c|c|}
\hline \multirow[b]{2}{*}{ Nerve } & \multirow{2}{*}{$\begin{array}{l}\text { Stimulation } \\
\text { Site }\end{array}$} & \multirow{2}{*}{$\begin{array}{l}\text { Recording } \\
\text { Site }\end{array}$} & \multicolumn{3}{|c|}{ Normal Values $\dagger$} \\
\hline & & & AMP & DL & $\mathrm{CV}$ \\
\hline median & wrist, elbow, axilla, SCF & thenar region & $>6$ & $<3.9$ & $>51$ \\
\hline ulnar & wrist, elbow, axilla, SCF & hypothenar region & $>8$ & $<3.0$ & $>51$ \\
\hline ulnar & wrist, elbow, axilla, SCF & first dorsal interosseous muscle & $>8$ & $<3.8$ & $>51$ \\
\hline radial & elbow, spiral groove, $\mathrm{SCF}$ & extensor digitorum communis muscle & $>6$ & $<3.0$ & NA \\
\hline musculocutaneous & axilla, SCF & biceps muscle & $>4$ & $<3.5$ & NA \\
\hline axillary & axilla, SCF & deltoid muscle & $>4$ & $<4.8$ & NA \\
\hline peroneal & ankle, fibular head, popliteal fossa & extensor digitorum brevis muscle & $>3$ & $<4.8$ & $>41$ \\
\hline peroneal & fibular head, popliteal fossa & tibialis anterior muscle & $>4$ & $<4.0$ & $>41$ \\
\hline posterior tibial & ankle, popliteal fossa & abductor hallucis muscle & $>6$ & $<5.6$ & $>41$ \\
\hline femoral & inguinal groove & rectus femoris muscle & $>4$ & $<6.0$ & NA \\
\hline facial & mastoid foramen & facial muscles & NA & NA & NA \\
\hline
\end{tabular}

* Reprinted with permission from Youmans JR (ed): Neurological Surgery, ed 3. Philadelphia: WB Saunders, 1990. SCF = supraclavicular fossa. For a more in depth analysis, see Table 5-2 in Kimura, 2000.

$\dagger$ Normal values are for young adults and vary from laboratory to laboratory. Some normal values in this table are courtesy of the EMG laboratory, The Cleveland Clinic.

licis brevis or flexor pollicis longus muscles. ${ }^{11}$ Sensory findings in the thenar eminence occur in contradistinction to carpal tunnel syndrome. Anterior osseous nerve compression just distal to the pronator teres will affect the flexor pollicis longus, pronator quadratus, and the radial side of the flexor digitorum profundus muscles. Conduction velocities will be normal, but EMG studies will be positive in the aforementioned muscles.

The ulnar nerve is most commonly injured at the elbow where it is superficial in the olecranon groove. Motor conduction velocities measured above, across, and below the elbow reveal a slowing across the elbow (Fig. 5). Patients with motor conduction velocities higher than $40 \mathrm{~m} / \mathrm{sec}$ may be watched for 6 to 8 weeks, but those with velocities less than $30 \mathrm{~m} / \mathrm{sec}$ should undergo surgery promptly. ${ }^{97}$ To a lesser extent the ulnar nerve may be entrapped at the wrist or in the Guyon canal. Distal latencies and EMG studies may be abnormal. ${ }^{2}$

The radial nerve is commonly involved in the spiral groove and supracondylar portion of the humerus as well as in the forearm proximal and distal to the supinator muscle. Motor conduction studies are performed in the forearm and sensory testing is possible by using the superficial radial nerve. Conducting EMG studies of selected muscles innervated by the radial nerve is helpful in localizing the site of compression..$^{15}$ Less afflicted nerves in the upper extremity at the shoulder girdle are axillary, musculocutaneous, dorsal scapular, suprascapular, and long thoracic nerves. The presence of abnormalities on EMG of the muscles innervated by the specific nerve, but the absence of paraspinal muscle changes can aid in the diagnosis. ${ }^{36}$

Thoracic outlet syndrome involves the lower trunk of the brachial plexus, made up of C-8 and T-1 roots, which are compressed by the cervical first rib. Electromyographically demonstrated abnormalities occur in the hand muscles, and sensory conduction from the fifth finger compared with the index finger will show delayed latencies or a reduction in amplitude. Supraclavicular motor stimulation and recording in distally innervated muscles and, more recently, evoked response monitoring together with recording distally at the Erb point have been found to be helpful. ${ }^{8}$

\section{Entrapment Syndromes in the Lower Extremity}

Entrapment syndromes in the lower extremity occur less frequently, but are more likely to be acutely traumatic. The femoral nerve may be injured proximal or distal to the inguinal ligament. Motor and sensory testing by using the saphenous nerve are available. An electromyographically recorded sampling of multiple muscles in the legs may be required to determine involvement of the lumbar plexus. ${ }^{138}$

The sciatic nerve is commonly injured in the gluteal region often by penetrating injury or posterior dislocation of the hip joint. Direct stimulation with the aid of needle electrodes, H-reflex stimuli, and EMG studies facilitate diagnosis and localization of injury to this nerve. ${ }^{138}$

The peroneal nerve enters the anterior compartment of the calf by passing from the popliteal fossa around the neck of the fibula. It is here that the nerve is usually compressed. A reduction in the combined MAP of the extensor digitorum brevis muscle or prolonged latency when stimulating in the popliteal fossa and below the fibular neck and recording distally, coupled with selective EMG studies is helpful in making the diagnosis of peroneal nerve injury at the fibular neck region. ${ }^{138}$

The posterior tibial nerve may be injured in the distal popliteal fossa or chronically compressed in the tarsal tunnel. This compression syndrome can be identified electrically with prolonged latencies of conduction across the retinaculum of the medial malleolus to the abductor hallucis muscle or digiti quinti pedis. Additionally, there will be abnormalities of the intrinsic muscles of the foot on EMG studies. ${ }^{153}$

Presently, MR imaging with the aid of $T_{1^{-}}$and $T_{2^{-}}$ weighted short tau inversion recovery is a useful tool in the evaluation of peripheral nerves. ${ }^{58}$

Cranial nerve testing, particularly that of cranial nerves seven and eight, will be discussed in a separate section. 


\section{Cervical and Lumbar Radiculopathies}

Cervical and lumbar radiculopathies less commonly require the use of electrodiagnostic studies with the advent of high-quality MR imaging and CT myelography. Nonetheless, separating radiculopathy from more peripheral pathological entities, or assessing which nerve root is the cause of a patient's symptoms may require EMG. Motor and sensory amplitudes are normal, and denervation abnormalities are present in two paraspinal muscles and two extremity muscles common to a cervical or lumbar nerve root. The hand F-response or S-1 root H-reflex may be abnormal. ${ }^{109}$

Plexopathies, particularly the brachial ones are commonly affected by trauma (motor vehicle accident, gunshot wound). With this disease entity a combination of EMG-demonstrated abnormalities-reduced sensory amplitudes with normal paraspinal EMG - is found. The additional use of supraclavicular motor stimulation and evoked response testing may be helpful. Intradural root avulsion will have preserved sensory responses. A similar workup for lumbosacral plexopathy is performed. ${ }^{152}$

Polyneuropathies are characterized by symmetrical distal motor and sensory deficits. Motor and sensory velocities and amplitude may be reduced with distal extremity muscle abnormalities on EMG. ${ }^{153}$

Myopathies may have reduced amplitudes of the combined MAPs. With successive stimulation, further decreases occur in amplitude. Motor conduction velocities are normal and EMG-demonstrated abnormalities reveal reduced recruitment and fibrillation. ${ }^{154}$

The recent development of magnetic stimulation of the cerebral cortex will be helpful in spinal cord and peripheral nerve diagnoses. ${ }^{108}$

\section{ELECTROENCEPHALOGRAPHY STUDIES}

\section{Background and Technology}

Electroencephalography is a noninvasive method of visualizing the ongoing physiology of the brain by recording the potential differences between two points, one or both of which are located on the scalp. The recorded signals are amplified and displayed, reflecting the movement of electrical charges in the brain.

The electroencephalogram in humans was first used in 1924 by Hans Berger, a professor of psychiatry at the University of Jena in Germany. His first records involved subcutaneous electrodes placed in the area of skull defects, and his first publication appeared in $1929 .{ }^{41}$ Several years later he was able to use a galvanometer to amplify these signals. Unfortunately, this significant discovery was unrecognized until 1934, when Adrian and Matthews confirmed the value of his work. ${ }^{3}$ Gibbs and Lennox were the first to describe the characteristic changes of epilepsy on EEG. ${ }^{20}$ Also, in 1934 Jasper $^{62}$ started his work on the explanation of the origin of cortical rhythms demonstrated on EEG and their regulation by the thalamus.

Recorded EEG voltages represent the summed postsynaptic potentials from large populations of cortical neurones, which are activated by thalamocortical input. These potentials act as a dipole, with a negative and a positive pole. They are created by the flow of the current (electri- cal circuit) as a result of postsynaptic input at different points along the neurone (Fig. 6). Biological tissues are three-dimensional electrical conductors and are therefore volume conductors. The potentials are by and large generated by cortical neurones lying parallel to the surface of the scalp so that the single dipole is oriented at a right angle to the cortical surface. Thus it follows that electrodes placed anywhere within the volume will record a potential difference with current flow. Only if the two electrodes lie on the same isopotential line with regard to the current flow will they fail to record a potential difference (Fig. 7). ${ }^{23}$ With this in mind, electrodes are placed on the scalp to take advantage of symmetrical coverage in the sagittal and coronal planes (Fig. 8). ${ }^{64}$ Recordings are performed using a bipolar technique in which potential differences are measured between adjacent electrodes in a chain, or potentials at all points are measured against a common reference. The former relies on the localization of a generator on a phase reversal occurring at the same electrode in two montages that are at right angles to each other; in the latter procedure, reliance is placed on amplitude measurements. With monopolar recording, the highest amplitude would be recorded at the $\mathrm{F}_{7}$ electrode (Fig. 9).

To understand the EEG machine and its recordings, some basic terminology in electrical measurement must be advanced. One coulomb (C) is equal to the charge of $6 \times 10^{18}$ electrons. One ampere $(\mathrm{A})$ of current is equal to the flow of one coulomb of charge per second $(1 \mathrm{C} / \mathrm{sec})$. Current flows from positive to negative potentials, and one joule $(\mathrm{J})$ of energy is expended when one coulomb of charge is moved across a potential of $1 \mathrm{~V}$. Voltage (V) is measured between two points and is the electromotive force. Resistance is measured in joule-seconds per coulombs-squared, or ohms $(\Omega)$. One ohm is the resistance $(R)$ that will dissipate one joule of energy when 1 ampere of current (I) flows for one second (Ohm's law is $\mathrm{V}=\mathrm{I} \times \mathrm{R}$ ).

A capacitator is a device that stores separate charges. It has two conducting plates situated close together but separated by an insulator. The movement of charges causes a current to flow, but not across the plates. An inductor is made of coils of wire around a magnetic field that is generated by current in the wire itself. The number of turns of wire increases the magnetic field strength of the current and is used to increase the induced voltage. The power source is expressed in joules per second or watts or voltage, and amperage. ${ }^{23}$

Originally, vacuum tubes were the active circuit elements used to record and amplify small potentials; now, semiconductors transistors and integrated circuits are used. Note that impedance is a combination of resistance, capacitator reactance, and inductive reactance. These usually can be ignored on EEG.

The EEG machine has 16, 20, 24, 32, or 64 channels for recording output to an oscilloscope, paper, or digital reformatting (Fig. 10). Surface electrodes are usually made of silver or silver and silver chloride; subdermal electrodes usually consist of platinum. The scalp electrodes record potentials with the aid of conductive paste sealed with collodion (Fig. 11). Distal electrodes plug into a jackbox labeled in accordance with the international 10-20 system of electrode designation. ${ }^{18,64}$ From here, inputs are carried 
to the montage (or the specific electrode recording arrangement on the scalp) selector board of the EEG machine. ${ }^{40}$ From that point, the EEG signals $(\mu \mathrm{V}$ or $\mathrm{mV})$ are amplified by preamplifiers. The amplification factor is called a "gain." Sensitivity is measured in micro- or millivolts per centimeter, and defines the amount of voltage needed to deflect the EEG pen a given distance. Typical sensitivities used are between 7 and $10 \mu \mathrm{V} / \mathrm{mm}$. Filters are used to attenuate and discard a low frequency $(<0.5$ $\mathrm{Hz}$ ), and there is a high frequency cutoff of $70 \mathrm{~Hz}$. In addition, a $60-\mathrm{Hz}$ notch filter is required to remove electrical noise. Grounding the patient and machine through the EEG machine is important to prevent ground loops of current between a patient and the machine ground..$^{85}$

\section{Electroencephalographic Patterns}

Normal Patterns. Normal electroencephalographic patterns vary with age and level of consciousness. ${ }^{56}$ The following patterns discussed refer to those in an adult. The occipital/alpha rhythm is a bilateral, symmetrical, posterior $8-$ to $13-\mathrm{Hz}$ pattern with amplitudes of 20 to $60 \mu \mathrm{V}$. It is recorded in an awake patient with his or her eyes closed (Fig. 12); it is attenuated by opening of the eyes. Slower rhythms without mixed fast rhythms are abnormal. ${ }^{87}$ The central rhythm pattern seen in an awake, relaxed patient is 7 to $12 \mathrm{~Hz}$ and has a comb-and-wicket pattern because of the rounded positive phase and the sharp peak to the negative phase. The amplitude is less intense than that of the alpha rhythm. The rhythm is bilateral, but may be asymmetrical, and is sustained or intermittent. It is attenuated by touch and movement of an extremity, an effect that may be bilateral. At times a more rapid, lower voltage may be seen. ${ }^{72}$ The pattern in the frontocentral area consists of varying frequencies, but resides in the $\beta$ range ( $>$ $13 \mathrm{~Hz}$ ). The frequency bands may be 18 to $25 \mathrm{~Hz}$, less commonly 4 to $16 \mathrm{~Hz}$, and rarely higher than $35 \mathrm{~Hz}{ }^{72}$ Temporal patterns may reveal varying rhythms: posteriorly in the $\alpha$ range and anteriorly, particularly with drowsiness, at ranges of 5 to $7 \mathrm{~Hz}{ }^{16}$

Sleep has four recognizable stages on EEG. Stage 1 occurs during drowsiness when there is a dropout of the $\alpha$ rhythm and the presence of vertex sharp waves. Rapid eye movement sleep, as revealed on electroculograms, occurs in the near-awake state. Slow and $\beta$ rhythms may alternate. Stage 2 begins as drowsiness deepens and is characterized by spindling at 12 to $15 \mathrm{~Hz}$ in the parasagittal area, vertex slow sharp waves, and K-waves that are high-voltage slow waves, followed by a spindle at the vertex (Fig. 13). Stage 3 happens as sleep deepens, slower rhythms occur, and there are fewer K-waves. Stage 4 is a deep sleep and is characterized by delta $(2-4 \mathrm{~Hz})$ waves. Sleep, sleep deprivation, hyperventilation, various barbiturate agents, and photic stimulation may be used to activate or accentuate normal and epileptic patterns. ${ }^{16}$

Abnormal Patterns. Abnormalities on EEG are indicated by the alteration, attenuation, or disappearance of normal rhythms and the appearance of abnormal rhythms with or without significant changes in normal rhythms. The interpreter of EEG results should first describe the normal and/or dominant background activity in an individual patient. Frequency is measured in Hertz or cycles per second. Mean amplitude should be estimated, and re- sponse to eye opening and movement should be noted. Next, the abnormalities that do not form part of the background activity are described, including spikes, sharp waves, slow waves, and their amplitude. Furthermore, one must determine whether these abnormalities are focal or symmetrical, synchronizing or episodic. Algorithms exist to quantify slow waves or spikes and their location. ${ }^{99} \mathrm{~A}$ description of the activation procedures and their results should follow. Third, an opinion should indicate whether the record is abnormal and, if so, to what degree. Last, clinical correlation should be determined. ${ }^{17}$

Polymorphic $\delta(2-4 \mathrm{~Hz})$ waves on EEG are the most common sign of either structural or metabolic pathological features in the brain, although in diffuse gray matter disease there may be paroxysmal slow-wave discharge. The former indicates deafferentation of cortex from thalamus. ${ }^{42}$ Focal lesions such as a neoplasm or an abscess are associated with focal $\delta$ waves and desynchronization of background activity. With cerebral infarction, loss of focal activity and PLEDs may occur. Subdural hematomas may produce focal or diffuse slow-wave activity and sometimes reduction in amplitude ipsilateral to the clot. ${ }^{1} \mathrm{Head}$ injuries produce, based on the level of a patient's consciousness, slowing and disorganization of background activity. Focal damage will produce suppression of activity regionally or hemispherically. Late findings include slow-wave and epileptiform abnormalities. ${ }^{22}$

Criteria for the diagnosis of brain death on EEG requires a specific number of electrodes, their resistance and spacing, reduced sensitivities, attention to recording of extracerebral sources, time constants, and length of recording. ${ }^{149,158}$

\section{Epilepsy and EEG}

Epilepsy is a disorder of hyperirritability of cortex and/ or thalamus. Epileptiform abnormalities are the most common pathological features requiring electroencephalographic evaluation. Interictal (the time between clinical and electrographic seizures) abnormalities may be recorded by EEG. They consist of spikes (20-70 msec duration), sharp waves (70-200 msec duration), spike and slowwave complexes, paroxysmal slow waves, and PLEDs. Sharp wave and spikes are asymmetric, with a shorter upswing than fall of the pen. Their occurrence may be transient, occurring singly or in trains at varying frequencies. They should be paroxysmal and distinguished from background activity. There must be an abrupt change in polarity to give them their sharpness. Their duration must be less than $200 \mathrm{msec}$. The interictal discharges must have a physiological field (Fig. 14). ${ }^{17,89}$

Ictal (the time during a seizure) EEG activity is characterized by abnormal waveforms and patterns. It is variable in duration, but evolves over time and location. Patients are traditionally monitored by video, and abnormal behavior associated with electrographic changes should occur at the same time as or after the electroencephalographic changes to be caused by these electrical abnormalities, that is, a clinical seizure. Electrographic seizures may occur without a clinical change in behavior, however. ${ }^{106}$ The EEG and video monitoring is time-locked to behavior and electrical signals with the aid of an automatic spike or seizure detection algorithm that saves and plays back the previous 2 minutes and the length of the event. ${ }^{43-45}$ 
In the neonatal patient, ictal waveforms may be variable and tend to evolve. They may be focal or multifocal and associated with PLEDs, burst suppression, poor background, and high-voltage delta waves. These latter interictal and background findings indicate structural damage to the brain. ${ }^{68,69,94}$

The present general classification of seizures characterizes them as partial or generalized. Partial seizures may be simple (consciousness not impaired) or complex (consciousness impaired). In the former, ictal and interictal abnormalities are confined to the contralateral hemisphere. In the latter, discharge is unilateral or frequently bilateral and its onset may be obscured by muscle artifact or remoteness of scalp electrodes from the generator. Interictal abnormalities may be unilateral or bilateral and usually have an asynchronous focus. ${ }^{148}$

Generalized seizures are associated with the initial involvement of both hemispheres, consciousness may be impaired, and this impairment may be the initial symptom. Motor involvement is bilateral. Ictal changes on EEG are also bilateral. Interictal recordings may be normal in the genetic/idiopathic group, and the secondary group will have associated interictal and background abnormalities. Brief absence seizures have 3-second spike-and-wave discharges. An atypical absence of seizures may demonstrate an irregular pattern with interictal background changes. Myoclonic seizures have polyspike-and-wave ictal change. Clonic seizures are characterized by fast activity and slow waves. Tonic seizures have low-voltage fast activity. Tonic-clonic seizures have a rhythm of $10 \mathrm{~Hz}$ followed by a slow wave, and atonic seizures have polyspike-and-wave discharges. ${ }^{29,133}$

Electrocorticography involves obtaining the EEG recordings directly from the brain surface. This is performed by placing electrode grids or an array of electrodes with cotton wicks or carbon balls (Fig. 15). Amplitudes are such that sensitivities must be increased. Usually interictal data are recorded. Stimulation with after-discharge to delineate seizure focus has limited value. After-discharge may occur from less than 1 to $90 \mathrm{msec}$ after stimulation. ${ }^{112}$ Activation with thiopental or methohexital may be used. The value of ECoG lies in tailored resections of the temporal lobe and lesional extratemporal resection..$^{80,88}$

Intracranial recordings obtained to delineate a seizure focus, that is, lateralization and localization, may best be performed preoperatively with chronic video-EEG recording by using the appropriate depth or strip and grid electrodes. The onset of focal medial temporal lobe seizure activity is characterized by attenuation in background amplitude and a rapid buildup of low-voltage beta rhythms evolving to $18-$ to $25-\mathrm{Hz}$ high-amplitude discharges. A more regional onset may have attenuation in background followed by rhythmic $4-$ to $12-\mathrm{Hz}$ discharges. In the frontal lobe and extratemporal cortex, a change in interictal activity followed by a buildup of polyspike or spikeand-wave discharges can occur. ${ }^{76,132}$ Postictal attenuation and slow-wave activity may be lateralizing. ${ }^{118}$

\section{MAGNETOENCEPHALOGRAPHY}

Magnetoencephalography has developed during the last decade. ${ }^{107}$ It is a noninvasive equivalent to EEG and pro- vides better spatial delineation of surface electromagnetic data, particularly that which is brain activated, that is, evoked response signals. ${ }^{21}$

To record the magnetic fields induced by electrical activity of the brain requires an instrument sensitive to the signals and their frequency. The instrument presently used is a superconductivity quantum interference device, or SQUID magnetometer. ${ }^{33}$ It measures small variations in magnetic flux that gives rise to an electrical current (Josephson effect). ${ }^{65}$ The Biot-Savant law states that a magnetic field due to a small electric current, such as that from cerebral neurons, varies as the inverse square of the distance of the current source and directly with the current and the sine of the angle between the directions of the current and the vector leading to it. The cerebral magnetic field generated is on the order of 10-12 $t$, far less than the earth's magnetic field. ${ }^{121}$

The components of the SQUID consist of a detection coil that senses the magnetic field and transforms it into an electrical current that becomes the signal of the field, and an input coil that transforms the resulting current into a magnetic flux. The superconductivity current is then influenced by the magnetic flux. The ring may be biased at one weak link (Josephson effect) by a radiofrequency current or by a direct current in two weak links (Fig. 16). The signal is improved by further electronic manipulation and then stored for display and further analysis. The SQUID amplifier and detection coils are superconductivity devices and require some type of refrigerant (liquid helium). The SQUID ring is made of niobium and is cooled below $23^{\circ} \mathrm{K}$ when immersed in a bath of helium at $4.2^{\circ} \mathrm{K}$ (Fig. 17). ${ }^{121}$ The SQUID is then housed in a Dewar that insulates the outside ambient temperature from the super coolant. In addition, it is transparent to magnetic fields (Fig. 18). Magnetic and eddy current shielding is mandatory. Originally, by increasing the number and type of detector coils, only seven channels were available for recording. This first instrument had to be moved around the patient's head for recording; with an increasing number of channels, the instrument required shifting from one hemisphere to the other. ${ }^{21,71}$

Both EEG and MEG record electromagnetic signals in the range of milliseconds, whereas neuroimaging, which depicts anatomy, and positron or single-photon emission CT scanning, which measures blood flow or metabolism, record time in a range of minutes. The electrical potentials measured on EEG are volume potentials and are altered by dura mater, skull, and scalp. Magnetoencephalography is not influenced by these structures. Whereas the EEG measures a potential difference, MEG measures an absolute value that is perpendicular to the electrical current. This indicates that the magnetic fields are generated from an intracellular compartment. Furthermore, MEG measures the tangential dipole (Fig. 19) ${ }^{67}$ Using a spherical head model, EEG or evoked response source will be rotated $90^{\circ}$ to the magnetic field. The combined use of MEG and closely spaced electrodes for EEG will result in greater knowledge of both the tangential and radial components of the physiological signals (Fig. 20). On balance, MEG has fewer problems with cortical spatial localizations, but remains problematic with deep sources because of quick decay of the magnetic field. ${ }^{121}$ 
Laboratory data on the localization of action potentials in peripheral nerve physiology have provided insight into the spatial domain of the area of depolarization. The magnetic dipole is founded on the right hand rule that states that the fingers lie in the direction of the magnetic flow and the thumb points to the direction of propagation. Using room temperature sensors (toroids) that surround the nerve, investigators have studied postinjury regeneration. The nonuniform propagation has its clinical counterpart in the neuroma-in-continuity in humans. ${ }^{151}$

In neurological studies, MEG can reveal spreading depression in migraine attacks ${ }^{104}$ and polymorphic delta waves in cerebral infarction, ${ }^{146}$ but its special promise resides in magnetic source imaging ${ }^{4}$ and its combined use with EEG in seizure detection. ${ }^{137,139}$ In the latter use, MEG requires fewer correction factors, but EEG detects more basal current orientations and allows for chronic monitoring. Although MEG is more expensive, it provides a simpler picture; the reverse is true for EEG. In patients with nonlesional temporal lobe epilepsy MEG may help differentiate medial compared with lateral onset and spatial relationships between the lesion and irritative zone (Fig. 21). In patients with neocortical epilepsy MEG seems to be more sensitive than EEG. ${ }^{7}$ Furthermore, the merging of MEG and EEG with MR imaging will help delineate areas of epileptic activity and their relationship to lesional abnormalities and functionally important areas. ${ }^{121,136}$

Using event-related stimuli and MEG, colocalized with MR imaging, new insight has been gained into motor, speech, visual, and auditory physiology. More recently these same techniques have been used to identify neural plasticity (Figs. 22 and 23). ${ }^{52}$

\section{EVOKED POTENTIALS}

Evoked potentials are gross potentials extracted from EEG studies by the averaging of stimulus-locked signals. They are the CNS's response to a sensory stimulus delivered peripherally. ${ }^{13}$ The use of this methodology for the diagnosis of acute and chronic pathological features along the neuraxis, including cognitive deficits, is based on the original findings of Dawson ${ }^{24}$ and substantiated in laboratory animals by Donaghey and Numoto. ${ }^{28}$ The potentials complement EEG studies and coupled with MEG are coregistered by fiducials to MR imaging for source localization. Neurosurgeons most commonly use SSEP monitoring in posterior fossa and spinal surgery, the former being accompanied by BAEPs. Visual evoked potentials are used in selected intracranial surgeries around the optic chiasm and in prelesion recording during pallidotomy to avoid the optic tract. ${ }^{143}$ In performing this type of electrophysiological testing, the pathway for the stimulus to enter must be preliminarily evaluated, that is, vision, hearing, and peripheral nerve/spinal cord function. Evoked potential monitoring differs from EEG in that the signals have a low amplitude $(\mu \mathrm{V})$ and the averaging of a large number of trials must be performed to obtain good waveform resolution.

The following discussions of visual, brainstem auditory, and somatosensory evoked response protocols are based on the American EEG Society guidelines. ${ }^{38}$

Visual evoked responses are a result of patterned or unpatterned stimuli. The latter are used in patients unable to fixate on the stimuli. Additionally, flash stimuli are used with goggles, particularly in the operating room. Response wave peaks are N75, P100, and N145. The P100 is the most reliable response and considered the standard recording. Between four and 10 stimuli are presented per second, with a luminance of 8.2 candela $/ \mathrm{m} .{ }^{24}$ The visual angle will dictate macular vision or a larger portion of retina stimulated. Typically, a $32^{\circ}$ field with a 50-minute arc check is a large field. The patient is no closer than $70 \mathrm{~cm}$ to the stimulus screen. Analysis time is $250 \mathrm{msec}$, with a system bandpass of 1 to $100 \mathrm{~Hz}$. The P100 latency should replicate within $2.5 \mathrm{msec}$, with 100 to 200 stimuli per response. The recording electrodes are placed left, middle, and right occipital to midfrontal and a fourth channel is situated midfrontal to ear/mastoid (Fig. 24). Latency criteria, either ipsilateral or interocular, should not exceed 2.5 to 3 SDs higher than the mean. Criteria for an abnormal amplitude are its absence, its marked reduction, or an abnormally high interocular ratio. Clinically, the P100 peak latency and amplitude are the most useful measurement in half field patterned stimuli. At the time of testing an electroretinogram (electrode periocular and one scleral) can be obtained to differentiate retinal from optic pathway pathological features.

Brainstem auditory evoked potentials consisting of five peaks are to be differentiated on the electrocochleogram. There is some controversy regarding the second peak of the BAEP, that is, whether this is an action potential of the auditory nerve (Fig. 25). The convention has been that the peaks occurring over 10 to $15 \mathrm{msec}$ localize peak 1 to the eighth cranial nerve; peak 2 , to the cochlear nucleus; peak 3 , to the superior olivary complex; and peaks 4 and 5 merge to the lateral lemniscus and inferior colliculus. The stimulus is created with broad-band clicks generated from $100-\mathrm{Hz}$ rectangular pulses by using a standard audiometric speaker. For intraoperative use, small ear inserts can be used. Stimulus rates between 8 and 10 per second are best suited for delineating the various peaks. A bandpass filter 10 to 30 and 2500 to $3000 \mathrm{~Hz}$, and 12 to $24 \mathrm{~dB}$ octave for the low and high frequencies, respectively, are used. Results of 1000 to 4000 trials should be averaged to obtain good waveform for 10 to $15 \mathrm{msec}$. Electrodes are placed at $\mathrm{C}_{\mathrm{z}}$ and at each earlobe or mastoid. Criteria for clinically significant abnormalities are latencies of peak, inter-

TABLE 4

Normative latency values of BAEP*

\begin{tabular}{|c|c|c|c|}
\hline \multicolumn{2}{|c|}{$90 \mathrm{~dB}$ Above SL clicks (msec) } & \multicolumn{2}{|c|}{ Interwave latency (msec) } \\
\hline Wave & Mean \pm SD & Waves & Mean \pm SD \\
\hline I & $1.88 \pm 0.09$ & I-II & $1.19 \pm 0.21$ \\
\hline II & $3.07 \pm 0.17$ & I-III & $2.14 \pm 0.19$ \\
\hline III & $4.01 \pm 0.16$ & $\mathrm{I}-\mathrm{IV} / \mathrm{V}$ & $3.46 \pm 0.27$ \\
\hline IV/V & $5.36 \pm 0.21$ & $\mathrm{I}-\mathrm{V}$ & $4.09 \pm 0.24$ \\
\hline IV & $5.23 \pm 0.17$ & III-V & $1.93 \pm 0.26$ \\
\hline $\mathrm{V}$ & $5.93 \pm 0.25$ & V-VI & $1.60 \pm 0.28$ \\
\hline VI & $7.50 \pm 0.26$ & & \\
\hline
\end{tabular}

$* \mathrm{SL}=$ sensation level. Reprinted with permission from Feblot P, Uziel A: Detection of acoustic neuromas with brainstem auditory evoked potentials. Comparison between cochlear and retrocochlear abnormalities, in Courjon J, Mauguiere F, Revol M (eds): Clinical Application of Evoked Potentials in Neurology. New York: Raven Press, 1982. 
peak latencies or amplitude ratios more than 2.5 to 3 SDs from the mean (Table 4). During surgery of the posterior fossa, either intra- or extraaxial, the absence of all waves or Waves IV and $\mathrm{V}$ or prolonged internal latencies of Waves I to III or Waves III to V is highly abnormal. Interaural comparisons are important. Testing of BAEPs is helpful outside the operating room in the critical care unit in evaluating patients with head injuries (Fig. 26) or when MR imaging studies are not clear in delineating invasive tumors of the brainstem. ${ }^{34}$ Additionally, late evoked potentials on imaging studies have been used to evaluate cognitive disorders. ${ }^{115}$

Somatosensory evoked potentials are elicited by stimulating peripheral nerves transcutaneously by using a pulse width of 100 to $300 \mathrm{msec}$ and the rate of 3 to $5 \mathrm{~Hz}$. A pass bandwidth of 30 to $300 \mathrm{~Hz}$ is used. The recording should last $40 \mathrm{msec}$ for the median nerve and $60 \mathrm{msec}$ for the posterior tibial nerve. A designation of the components follows: EP is the propagated volley under Erb point, N13 is the stationary cervical potential recorded referentially from the dorsal neck, P14 is a subcortically generated far-field potential from scalp electrodes whose source is believed to be in the medulla, N18 is similar to P14 but localized to the brainstem thalamus, and N20 reflects activation of the cortical somatosensory area. Electrodes on the scalp are placed at C3 and halfway between P3 as well for $\mathrm{C} 4$ and $\mathrm{P} 4$, and referential recording areas. The absence of any obligate waveforms or the prolongation of interpeak latencies more than 2.5 to $3 \mathrm{SDs}$ greater than the mean is abnormal (Fig. 27).

In the lower extremity, LP is a stationary lumbar potential, and N34 is a subcortical far-field potential generated from the upper brainstem, and P37 reveals activation of the primary sensorimotor cortex. Recording loci are set at $\mathrm{T}-12$ as a reference and at other locations similar to those used with upper-extremity SSEPs. Criteria for abnormalities include the absence of obligate waveforms and the prolongation of the LP-P37 interpeak latency 2.5 to 3 SDs greater than the mean (Fig. 28).

Somatosensory evoked potentials are an important part of monitoring of the neuraxis in spinal cord or posterior fossa surgery (Fig. 29). Additionally, dermatomes may be a source of stimulus for entrance into the CNS. As with BAEPs, SSEPs may be a helpful tool in evaluating the comatose patient given that these potentials are not altered by coma or barbiturate agents (Fig. 30). Reversal of the N20-P20 has been used to identify the central sulcus, but one must be aware of the peculiar anatomy of the sulcus in each patient or the presence of a tumor appearing in the sulcus (Fig. 31). ${ }^{75}$

\section{ELECTROPHYSIOLOGICAL TESTING FOR INTRACRANIAL PROCEDURES}

\section{Posterior Fossa and Cranial Nerves}

In performing intracranial surgery that requires prolonged dissection and retraction of vital centers and cranial nerves, intraoperative electrophysiological monitoring of these structures is mandatory to assist the surgeon in localization as well as in assessing the extent of the manipulation of these structures. Cranial nerves two to 12 can be monitored by evoked response potentials (visual evoked potentials, BAEPs), triggered EMG, or a combination of the two. Except for cranial nerves two and eight, the remaining nerves can be monitored by compound MAP triggered by manipulation or direct nerve stimulation. The muscles innervated by a particular cranial nerve are recorded using small subdermal electrodes or surface electrodes around the orbit of the extraocular muscles. Methodology of evoked response monitoring has been discussed earlier in detail. Before embarking on evoked potential monitoring, testing of the visual apparatus for acuity, visual field perimetry, and color recognition should be performed. Likewise, the cochlear and vestibular system should be evaluated. The combination of SSEPs and BAEPs is helpful in assessing brainstem function during posterior fossa surgery; the use of SSEPs is also helpful in supratentorial surgery (Fig. 32).

Hearing may be evaluated with pure-tone audiometric testing in the range of 250 to $8000 \mathrm{~Hz}$. Speech sounds are located in the middle frequency range of 500, 1000, and $2000 \mathrm{~Hz} .{ }^{66}$ Intensity is measured in decibels; zero is barely audible. The scale is logarithmic to the base 10 . Hearing thresholds of 0 to $20 \mathrm{~dB}$ are normal; 20 to $40 \mathrm{~dB}$ indicates mild hearing loss; 40 to $55 \mathrm{~dB}$ indicates moderate hearing loss; 55 to $70 \mathrm{~dB}$ indicates moderately severe loss; 70 to $90 \mathrm{~dB}$ indicates severe loss; and $90 \mathrm{~dB}$ and higher indicate profound loss. ${ }^{145}$ Speech reception is performed with two-syllable words at softer levels until only $50 \%$ of the words can be heard. This should approach pure-tone thresholds in speech frequencies. Speech discrimination involves the presentation of phonetically balanced words well above the speech-reception thresholds. The list contains 50 monosyllabic words. Patients with sensorineural loss will demonstrate decreased speech discrimination ability. ${ }^{66,144}$

Through its peripheral neuroepithelial structures, the vestibular system signals the brainstem, cerebellum, and higher centers on the position of the head and retunes the body musculature. The otolith organs perceive linear acceleration, whereas the semicircular canals signal angular acceleration and deceleration. Normally, the bilateral system balances input to the CNS. The vestibular activation produces a deviation of the eyes (nystagmus) with a slow movement, whereas the central stimulus produces a rapid return. Abnormalities may be evaluated with electronystagmography testing by using surface electrodes laterally around the orbit and midline of the head. Spontaneous nystagmus with the patient's eyes closed or fixated and during positional changes and caloric stimulation may be performed..$^{50}$ The slow component is noted on the side of the destructive or cold-water irrigated ear (Figs. 33 and 34). ${ }^{8}$

The nerves most commonly monitored during surgery are cranial nerves seven and eight. In $1893 \mathrm{Krause}^{73}$ noted that low-current electrical stimulation of the seventh cranial nerve produced contractions in the facial muscles during sectioning of the eighth cranial nerve for tinnitus. In 1979 Delgado and colleagues ${ }^{25}$ reported on the first series of patients who had undergone intraoperative EMG monitoring of facial nerve stimulation during cerebellopontine angle surgery. This procedure enables the surgeon to locate and preserve anatomically and functionally the seventh cranial nerve during tumor removal. The motor units of the facial muscles may be activated by electrical or me- 
chanical stimulation, leading to a compound MAP between 0.1 and $2 \mathrm{mV}$. Subdermal needle electrodes are placed in the orbicularis oculi and oralis, nasalis, and mentalis. Spontaneous motor unit discharges and those triggered by direct stimulation are recorded. There are four

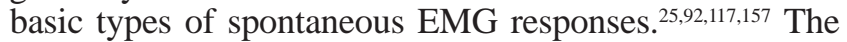
first is a brief nonrepetitive polyphasic discharge from brief contact with the nerve (Fig. 34). Note, however, that sustained repetitive, asynchronous motor unit discharges (trains) are a result of nerve irritation that is usually a result of traction of the nerve fibers. Manipulation should be discontinued and warm saline irrigation performed. If the irritation is minor, the nerve quiets within 1 to $2 \mathrm{~min}$ utes. A highly traumatized nerve may produce a sputtering audio discharge. Clonic (burst and silence) or multiphasic responses of increasing and decreasing electrical activity are characteristic of impending nerve injury. Direct electrical stimulation is the most important method of assessing nerve location and integrity. Initially, one explores the capsule by using $2 \mathrm{~mA}$ of monopolar stimulation. If there is no response, surgery may proceed. Once the nerve is identified, the current is reduced to 0.05 to 0.2 $\mathrm{mA}$. At the end of the procedure, thresholds for CMAP are established from distal to proximal directions along the nerve. ${ }^{123}$ Anatomical preservation in most large series exceeds $90 \%$, but physiological preservation may be $73 \%$, depending on the size of the tumor. ${ }^{57,120,150}$ There is a correlation between threshold stimulation proximally being equivalent to the distal nerve; in these patients, $88 \%$ maintained function. ${ }^{15}$ The lower threshold paralleled the higher degree of function. ${ }^{96,128}$

Cochlear nerve monitoring of action potentials in the setting of a large tumor is quite difficult or impossible, but may be performed in smaller tumors (Fig. 35). ${ }^{93}$ Thus, from a practical standpoint, BAEP monitoring is more widely used. The BAEP consists of five or more peaks within $10 \mathrm{msec}$ of high-intensity $(80-100 \mathrm{db}$ per sound level) repetitive clicks at a rate of 17 to 21 per second. The response is averaged over a number of trials (100-2000). Waves I, III, and V have the most clinical significance. In healthy volunteers the latency between Waves I and V is 4.5 msec $^{32}$ In small tumors, that latency may be greater than $5 \mathrm{msec}$, whereas large tumors may only show Wave I. During surgery, a change in amplitude, latency, or morphology represents insult to the nerve. Matthies and Samii $^{90}$ found that the loss of Waves I, III, and V was correlated with hearing loss; Wave III was sensitive and Wave V was specific. When choosing candidates for hearing preservation, patients should have hearing levels characterized by a speech reception threshold less than $30 \mathrm{~dB}$ and a speech discrimination sensitivity greater than $70 \% .{ }^{156}$ MacDonald, et al. ${ }^{84}$ reported an inverse correlation between extension into the fundus of the internal auditory canal. In addition, Ojemann found that extension of 0.5 to $18 \mathrm{~mm}$ into the posterior fossa correlated negatively. ${ }^{103}$

\section{Basal Ganglia}

With the advent of cerebral stereotaxy in humans in 1947 by Spiegel and Wycis, ${ }^{134,135}$ localization with air encephalography (and later ventriculography) was still somewhat inaccurate despite early brain atlases. ${ }^{122,141}$ Nonetheless, autopsy results in patients who had previously undergone stereotactic operations for Parkinson disease revealed adequate location and correlated with efficacy. ${ }^{51}$ Ventriculography has been abandoned for MR imaging or MR imaging/CT scanning fusion images. ${ }^{77} \mathrm{Er}-$ ror remains, however, particularly in the $\mathrm{z}$ axis. ${ }^{12}$

Initially, macrostimulation was relied on to increase tremor and/or to reveal abnormal signs of suboptimal location of an electrode such as contralateral numbness or forced contraction of the upper extremity. This was performed using a lesioning electrode $1.1 \mathrm{~mm}$ in diameter with a 3-mm exposed tip (Radionics, Burlington, MA). This would reflect the nearness to structures not to be lesioned, but gave no indication of exact location of the area to be lesioned.

Impedance monitoring, which measures resistance to an electrical current, gives crude differentiation of cerebral structures of nearly the same density. In 1961 Albe-Fessard, et al., ${ }^{5}$ reported the use of low-impedance microelectrodes to record evoked field potentials. Later, in 1968 Jasper and Bertrand ${ }^{63}$ used high-impedance electrodes, but the signal-to-noise ratio was poor. Today, technology has facilitated more clean single-unit recordings. This has permitted mapping of the motor and sensory nucleus of the thalamus and now the globus pallidus and subthalamic area. ${ }^{61}$

Microelectrodes made of tungsten or platinum/iridium with a tip diameter of 2 to $4 \mu \mathrm{m}$ and an impedance of 0.5 to $1 \mathrm{M} \Omega$ are advanced in protective stainless steel-guided tubes to $20 \mathrm{~mm}$ above the target. They are then advanced in small increments to the target by using a hydraulic drive. The signals are amplified and filtered (200-5000 $\mathrm{Hz}$ ). They are displayed on an oscilloscope and audio monitor. These signals can be digitized and stored. Microelectrode stimulation is applied at $300 \mathrm{~Hz}, 0.2-\mathrm{msec}$ width, 1 to $100 \mu \mathrm{A}$ at 1 - to 4 -second trains. ${ }^{61}$

The Vim is a preferred site for lesioning or chronic stimulation in patients with parkinsonian, essential, or cerebellar tremor. ${ }^{100}$ The target is one half the width of the third ventricle plus $11.5 \mathrm{~mm}$, rostral to the posterior commissure according to the Guiot's quadrilateral space bounded by a line parallel to one half the height of the thalamus and the anterior commissure-posterior commissure line divided into twelfths (extending forward to the ventrooralis posterior), and 1.5 to $3 \mathrm{~mm}$ above the intercommissural plane (Fig. 36). ${ }^{47,142}$ Cell responses with spontaneous high frequency and amplitude, which may or may not be synchronous with tremor, are recorded. In addition, irregular tremor-independent cellular discharge can occur (Fig. 37). The Vim, anterior to the ventrocaudal nucleus (somatosensory) of the thalamus, has cells that are responsive to joint motion (kinesthetic cells; Fig. 38). The arm area is represented medial to the leg. Microelectrode stimulation produces paresthesia on the contralateral side of the body and suggests the electrode is posterior in tactile nucleus. Therefore, the electrode should be moved forward at least $2 \mathrm{~mm}$. Evoked response recordings, particularly those obtained from afferent fibers (muscle spindle) are helpful (Fig. 39). Microelectrode stimulation of the internal capsule is performed to confirm the lateral boundary of a target. ${ }^{142}$ 
Pollak and colleagues ${ }^{116}$ have popularized subthalamic stimulation for the disabling akinesia of Parkinson disease. The starting target is $12 \mathrm{~mm}$ lateral and 2 to $4 \mathrm{~mm}$ posterior to the midcommissural point and $3 \mathrm{~mm}$ below the anterior commissural-posterior commissural line. The cell responses recorded in the STN are high amplitude, with some variation in activity at 25 to $45 \mathrm{~Hz}$. Firing of neurones can be modulated by passive or active motion. The arm is represented lateral to the leg. There is, on passing into the substantia nigra, a higher rate of firing at 60 to $90 \mathrm{~Hz}$, which is more regular (Fig. 40)..$^{59}$

During pallidotomy, the initial target is situated 20 to 22 $\mathrm{mm}$ lateral, and 2 to $3 \mathrm{~mm}$ anterior to the midpoint of the intercommissural line and 3 to $5 \mathrm{~mm}$ below the anterior commissural-posterior commissural line ${ }^{74}$ Characteristically, cells in the globus pallidus externus are of two types: one with low frequency $(10-20 \mathrm{~Hz})$ and the other with a higher frequency $(30-60 \mathrm{~Hz})$. Both are irregular and interrupted by pauses. The globus pallidus internus has neurones firing at a regular rate between 20 to $200 \mathrm{~Hz}$ (mean $80 \mathrm{~Hz}$ ). Cells responsive to passive or active motion can be identified (Fig. 41). ${ }^{147}$ The leg responses are represented, to some degree, more dorsally. ${ }^{26}$ Tremor-synchronous cells have been identified. ${ }^{140}$

Alternatively, semi-microelectrode recording with more sophisticated online computer analysis may be performed using Fourier transform, which is similarly used in locating neural generators in EEG studies. ${ }^{53}$ Postlesioning recordings are obtained (Fig. 42). Furthermore, wavelet and complexity techniques coupled with clinical features can be incorporated into training a neural network to predict outcome and hazard for lesioning at any recorded locus along the electrode tract. ${ }^{49}$

\section{Functional Mapping}

In this decade cortical localization has become a preoperative noninvasive methodology with intraoperative confirmation. This is due to the advances in computer imaging (functional MR imaging) and evoked responses to MEG- or EEG-triggered functional MR imaging. ${ }^{30,110}$ Transcranial magnetic stimulation has been developed during the past decade to be highly localizing and combined with neuroimaging to study connectivity of neural networks. ${ }^{108}$ The pulse of the magnetic field passes through the cranium and induces an electrical current. The effect may be inhibitory or excitatory and similar to the effect of direct electrical stimulation as described by Penfield and Roberts. ${ }^{113}$ For localization of transcranial magnetic stimulation during EEG and/or MEG the recording positions on the scalp along with fiducial markers can be digitized. The fiducials can then be identified on subsequent MR images, and then coregistration of the results of the two studies can be performed. ${ }^{37}$ Vision, speech, and motor activities can thus be mapped.

Functional MR imaging involves the activation of brain areas by using event-related techniques, magnetic stimulation, or naturally occurring events such as seizure or spike detection EEG to increased blood flow and change in blood oxyhemoglobin and deoxyhemoglobin levels. This method uses a $\mathrm{T}_{2}$-weighted echo-planar imaging procedure that is sensitive to the blood oxygenation level-dependent contrast. ${ }^{130}$ These techniques have been used for localizations of seizure focus and speech lateral- ization in patients undergoing presurgical evaluation..$^{35,131}$ Even with the advances in neuroimaging and manipulation of electromagnetic data, direct cortical stimulation in the awake patient remains the gold standard; however, using triggered EMG in selected muscles, the motor cortex can be mapped in an anesthetized patient (Fig. 43). The monumental work by Penfield and colleagues ${ }^{11,112}$ details this field. Motor mapping can supplement SSEP recording with subdural electrode strips or grids (Fig. 44). This may be correlated with neuronavigational techniques. ${ }^{9}$ In recent years Ojemann, et al., ${ }^{101}$ have expanded our knowledge of cortical localization of language (Fig. 45). In a more practical way, Haglund, et al., ${ }^{48}$ reported that resection of brain and tumor margin extending to less than $1 \mathrm{~cm}$ of identified language cortex will, with a high probability, produce a postoperative language deficit.

Cortical or subcortical white matter pathway stimulation involves the use of an electrical generator to deliver biphasic current through monopolar or bipolar electrodes to the cortex for 4 seconds at $60 \mathrm{~Hz}(0.5$-to $1 \mathrm{msec}$ duration, voltage $1 \mathrm{~V}$ or $2 \mathrm{~mA}$ for initial threshold; Fig. 46). Identifying the motor cortex is accomplished by direct stimulation and the consequent production of motor movements. Applying stimulation to the premotor cortex may produce arrest of muscle activity or change in muscle tone. Furthermore, stimulation of the postcentral gyrus produces paresthesias in the contralateral limb or side of the body. Initially, the face area lends itself very well to localization of the sensorimotor area (Fig. 47) ${ }^{114}$ The current should then be increased to response or after-discharge levels and then reduced $2 \mathrm{~mA}$ below the after-discharge threshold. After performing face area localization, language cortical areas are identified by noting interruptions in speech, counting, or naming during stimulation. ${ }^{113}$ Speech arrest is more likely to be related to a language disturbance when it is associated with misnaming, preservation, confusion in number counting, or a retained ability to talk. ${ }^{82}$ Reading and memory areas may also be identified using similar techniques. ${ }^{102}$ Electrocorticography will have been performed first. Stimulation techniques for localization of an epileptic focus producing after-discharge (Fig. 48) are no longer used as often-given the more sophisticated imaging and EEG studies that can be performed preoperatively-but may indicate the epileptogenic region. Interictal epileptiform sharp waves or spikes are noted; based on their location and type of surgery to be performed, the areas they encompass are resected, particularly in the frontal and extratemporal cortices. The value of postoperative ECoG is dictated by the cortices involved and perilesional cortex. ${ }^{10,31,118}$

\section{SPINAL CORD MONITORING}

Spinal cord monitoring is commonplace today, particularly in complex spine cases, for example, those requiring scoliosis, decompression, or reconstructive spine surgeries. Circumstances that require monitoring include impending or actual neurological deficit or endangered vascular supply to the spinal cord. The techniques available for assessing nerve root and spinal cord function are monitoring of SSEPs, dermatomal evoked potentials, triggered EMG, and motor evoked potentials.

Somatosensory evoked potentials reflect posterior col- 
umn conduction. Neural structures of stimulation include the posterior tibial, median, and ulnar nerves. The latter is unique in its limited entrance into the spinal cord and role as an effective monitor of the brachial plexus in the patient while in a particular position during surgery. ${ }^{125}$ Spinal cord compression may be increased by turning, positioning, or extending the neck (Fig. 49). ${ }^{124}$ The SSEPs are sensitive to the inhalation of anesthetic agents; thus the use of narcotics such as fentanyl, propofol, and midazolam are appropriate.

Monitoring of nerve roots can be performed by stimulating a dermatomal field. It is most effective when undertaken in patients with recent nerve root compromise so that with decompression, improved amplitudes may be seen. Chronic nerve deficits or acute surgical nerve root injuries will not reflect change with adequate decompression. Furthermore, spinal cord deficit may prevent entrance of afferent volleys. Triggered EMG is helpful in revealing intraoperative nerve root injury from pedicle screw placement. The screw may be stimulated and the CMAP is recorded. If the screw encroaches on the nerve, a CMAP will be recorded at low thresholds $(<5 \mathrm{~mA}){ }^{78}$ Alternatively, the muscles innervated by the nerve root can be recorded on EMG. An irritated nerve will be reflected by CMAP with a high reliability. ${ }^{105}$

More satisfactory monitoring of the ventral portion of the spinal cord can be achieved using transcranial electrical or magnetic stimulation, which induces an electrical current within cerebral tissues of the motor cortex and activates the corticospinal tract. ${ }^{14}$ The CMAP will be recorded at the tibialis anterior muscle (Fig. 50). ${ }^{46}$ This method of recording has been evaluated in laboratory animals. ${ }^{95}$ From a practical standpoint, transcranial electrical stimulation is preferred by using constant-voltage or current stimulators with a single or multiple pulses lasting as long as $0.5 \mathrm{msec}$. Note that side effects occur rarely. ${ }^{83}$

Last, a decision algorithm based on neurophysiological monitoring during complex spine surgery is a useful decision-making tool (Fig. 51). ${ }^{126}$

\section{CONCLUSIONS}

A basic knowledge of neurophysiology permits understanding of electrophysiological testing as well as its normal and abnormal values. The evolving fields of computer science and electrical engineering have facilitated new methods of cortical stimulation (transcranial magnetic or electrical, magnification and stimulation of evoked signals, and source localization). The latter signals can be coregistered with CT images. Thus, preoperative mapping may be useful in strategic surgical planning and may be correlated with intraoperative pathological features and mapping. Evoked potential monitoring coupled with central and peripheral evoked motor stimulation has led to a higher degree of safety in patients undergoing intraspinal and posterior fossa surgery. Intraoperative recording stimulation facilitates MRdirected placement of therapeutic electrodes in basal ganglia, the thalamus, and the subthalamic region. We await further advances, particularly in source imaging.

\section{Acknowledgment}

I thank Anthony K. Sestokas, Ph.D., for annotations to Figs. 5, 32, 34 , and 44.

\section{References}

1. Abraham K, Marsan CA: Patterns of cortical discharges and their relation to routine scalp electroencephalography. Electroencephalogr Clin Neurophysiol Suppl 10:447-461, 1958

2. Adelaar RS, Foster WC, McDowell C: The treatment of the cubital tunnel syndrome. J Hand Surg (Am) 9A:90-95, 1984

3. Adrian ED: The Discovery of Berger Handbook of Electroencephalography and Clinical Neurophysiology. Amsterdam: Elsevier Scientific, 1971 (Reference unverified)

4. Aine CJ, Bodis-Wollner I, George JS: Generators of visually evoked neuromagnetic responses. Spatial-frequency segregation and evidence for multiple sources. Adv Neurol 54: $141-155,1990$

5. Albe-Fessard D, Arfel G, Guiot G, et al: Identification et délimitation précise de certaines structures souscorticales de l'homme l'électro-physiologie. CR Acad Sci 243:2412-2414, 1961

6. Barkhaus PE, Nandedkar SD: Recording characteristics of the surface EMG electrodes. Muscle Nerve 17:1317-1323, 1994

7. Baumgartner C, Pataraia E, Lindinger G, et al: Neuromagnetic recordings in temporal lobe epilepsy. J Clin Neurophysiol 17:177-189, 2000

8. Bernstein L, McMurtry CA: Neuro-otology, in Youmans JR (ed): Neurological Surgery: A Comprehensive Reference Guide to the Diagnosis and Management of Neurosurgical Problems, ed 3. Philadelphia: WB Saunders, 1990, Vol 1, pp 557-581

9. Black PM (ed): Cerebral cortical surgery with functional mapping. Techn Neurosurg 7:1-80, 2001

10. Britton JW, Cascino GD, Sharbrough FW, et al: Low-grade glial neoplasms and intractable partial epilepsy: efficacy of surgical treatment. Epilepsia 35:1130-1135, 1994

11. Buchthal F, Rosenfalck A, Trojaborg W: Electrophysiological findings in entrapment of the median nerve at wrist and elbow. J Neurol Neurosurg Psychiatry 37:340-360, 1974

12. Bullard DE, Nashold BS Jr: Impedance recording in functional neurosurgery, in Gildenberg PL, Tasker RR (eds): Text Book of Stereotactic and Functional Neurosurgery. New York: McGraw Hill, 1998, pp 949-954

13. Burgess RC: Event-related potentials. J Clin Neurophysiol 9: 455, 1992

14. Cadwell J: Optimizing magnetic stimulator design, in Levy WJ, Cracco AT, Barker AT, et al (eds): Magnetic Motor Stimulation: Basic Principles and Clinical Experience. New York: Elsevier Science, 1992, pp 291-301

15. Carpenter DE, Subramony SH: Electromyography, in Youmans JR (ed): Neurological Surgery: A Comprehensive Reference Guide to the Diagnosis and Management of Neurological Problems, ed 3. Philadelphia: WB Saunders, 1990, Vol 1, pp 470-499

16. Celesia GG, Paulsen RE: Electroencephalographic activation with sleep and methohexital. Comparative usefulness in the diagnosis of epilepsy. Arch Neurol 27:361-363, 1972

17. Chatrian GE: A glossary of terms most commonly used by clinical electroencephalographers. Electroencephalogr Clin Neurophysiol 37:538-548, 1974

18. Chatrian GE, Lettich E, Nelson PL: Modified nomenclature for the "10\%" electrode system. J Clin Neurophysiol 5: 183-186, 1988

19. Chaudhry V, Cornblath DR: Wallerian degeneration in human nerves: serial electrophysiological studies. Muscle Nerve 15: 687-693, 1992

20. Cobb WA: The first forty years of EEG, in Remond A, Cobb WA (eds): Handbook of Electroencephalography. Amsterdam: Elsevier Scientific, 1971 (Reference unverified)

21. Crum DB: The design and use of dewars for biomagnetic measurements, in Weinberg H, Stroink G, Katila T (eds): Biomagnetism: Applications \& Theory. Proceedings of the 
Fifth International Conference on Biomagnetism. New York: Pergamon Press, 1985, pp 21-28

22. Culebras A, Henry CE, Williams GH Jr: Evaluation of intracranial space-occupying lesions by computed tomography and electroencephalography. A comparison. Cleve Clin Q 45: 275-280, 1978

23. Daly DD, Pedley TA: Current Practice of Clinical Electroencephalography, ed 2. New York: Raven Press, 1990

24. Dawson GD: Cerebral responses to electrical stimulation of peripheral nerves in man. J Neurol Neurosurg Psychiatry 10:137-140, 1947

25. Delgado TE, Buchheit WA, Rosenholtz HR, et al: Intraoperative monitoring of facial muscle evoked responses obtained by intracranial stimulation of the facial nerve: a more accurate technique for facial nerve dissection. Neurosurgery 4:418-421, 1979

26. DeLong MR: Activity of pallidal neurons during movement. J Neurophysiol 34:414-427, 1971

27. Didier C, Shahani B: Electromyography, in Wilkins RH, Rengachary SS (eds): Neurosurgery. New York: McGraw Hill, 1985, pp 174-183

28. Donaghey RN, Numoto M: Prognostic significance of sensory evoked potential in spinal cord injury, in Proceedings of the Seventeenth Spinal Cord Injury Conference. Bronx. New York: Veterans Administration Hospital 1969, pp 251-257

29. Dreifuss FE: Overview: Phenomenology, in Engel J Jr, Pedley TA (eds): Epilepsy: A Comprehensive Textbook. Philadelphia: Lippincott-Raven, 1997, pp 515-524

30. Engel J Jr: Overview of functional neuroimaging in epilepsy, in Henry TR, Duncan JS, Berkovic SF (eds): Functional Imaging in the Epilepsies. Philadelphia: Lippincott Williams \& Wilkins, 2000, pp 1-27

31. Engel J Jr, Driver MV, Falconer MA: Electrophysiological correlates of pathology and surgical results in temporal lobe epilepsy. Brain 98:129-156, 1975

32. Erwin CW, Erwin AC: The use of brainstem auditory evoked potential in intraoperative monitoring, in Russell GB, Rodichok LD (eds): Intraoperative Monitoring. Boston: Butterworth-Heinemann, 1995, pp 135-158 (Reference unverified)

33. Fagaly RL: Neuromagnetic instrumentation, in Susumu S (ed): Magnetoencephalography. New York: Raven Press, 1990, pp 11-32

34. Fischer C, Mauguiere F, Echallier JF, et al: Contribution of brainstem auditory evoked potentials to diagnosis of tumors and vascular diseases. Adv Neurol 32:177-185, 1982

35. Fried I: Functional neuroimaging in presurgical localization of essential cortical processing zones, in Henry TR, Duncan JS, Berkovic SF (eds): Functional Imaging in the Epilepsies. Philadelphia: Lippincott Williams \& Wilkins, 2000, pp 297-303

36. Gelberman RH (ed): Operative Nerve Repair and Reconstruction, ed 2. Philadelphia: JB Lippincott, 2001

37. Gevins A, Brickett P, Costales B, et al: Beyond topographic mapping: towards functional-anatomical imaging with 124channel EEGs and 3-D MRIs. Brain Topogr 3:53-64, 1990

38. Gilmore RL (ed): American electroencephalographic society guidelines in electroencephalography, evoked potentials, and polysomnography. J Clin Neurophysiol 11:1-147, 1994

39. Glasser HS: Compound action potentials of a band of fibers. Ohio J Sci 41:145-159, 1941

40. Gloor P: Applications of volume conductor principles to montage design. Am J EEG Technol 17:5-10, 1977

41. Gloor P: Hans Berger and the discovery of the electroencephalogram. Am J EEG Technol 9:1-8, 1969 (Reference unverified)

42. Gloor P, Ball G, Schaul N: Brain lesions that produce delta waves in the EEG. Neurology 27:326-333, 1977

43. Gotman J: Automatic recognition of epileptic seizures in the
EEG. Electroencephalogr Clin Neurophysiol 54:530-540, 1982

44. Gotman J, Gloor P: Automatic recognition and quantification of interictal epileptic activity in the human scalp EEG. Electroencephalogr Clin Neurophysiol 41:513-529, 1976

45. Gotman J, Ives JR, Gloor P: Automatic recognition of interictal epileptic activity in prolonged EEG recordings. Electroencephalogr Clin Neurophysiol 46:510-520, 1979

46. Gugino LD, Aglio LS, Segal ME, et al: Use of transcranial magnetic stimulation for monitoring spinal cord motor paths. Semin Spine Surg 9:315-336, 1997 (Reference unverified)

47. Guiot G, Derome P: The principles of stereotaxic thalamotomy, in Schneider RC, Kahn EA, Crosby EC, et al (eds): Correlative Neurosurgery, ed 3. Springfield, IL: Charles C Thomas, 1982, Vol 2, pp 481-505

48. Haglund MM, Berger MS, Shamseldin M, et al: Cortical localization of temporal lobe language sites in patients with gliomas. Neurosurgery 34:567-576, 1994

49. Hamilton JL, Micheli-Tzanakou E, Lehman RM: Waveletand complexity-based neural networks for lesion targeting in pallidotomy. 50th Annual Meeting of the Congress of Neurological Surgeons. San Antonio, Texas. San Antonio: CNS, 2000 (Abstract) (Reference unverified)

50. Hart CW: The optokinetic test and the ENG test battery. Ann Otol Rhinol Laryngol Suppl 90:2-6, 1981

51. Hassler R, Mundinger F, Riechert T: Correlations between clinical and autoptic findings in stereotaxic operations of parkinsonism. Confin Neurol 26:282-290, 1965

52. Henry TR, Duncan JS, Berkovic SF (eds): Functional Imaging in the Epilepsies. Philadelphia: Lippincott Williams \& Wilkins, 2000

53. Hjorth B: Principles for transformation of scalp EEG from potential field into source distribution. J Clin Neurophysiol 8: 391-396, 1991

54. Hodes R, Larrabee MG, German W: The human electromyogram in response to nerve stimulation and the conduction velocity of motor axons: studies on normal and on injured peripheral nerves. Arch Neurol Psychiatry 60:340-365, 1948

55. Hong CZ, Yu J: Electrophysiologic recovery of acute conduction block of rat tail nerve. Arch Phys Med Rehabil 70: 205-209, 1989

56. Horowitz P, Hill W: The Art of Electronics. New York: Cambridge University Press, 1981

57. House JW, Brackmann DE: Facial nerve grading system. Otolaryngol Head Neck Surg 93:146-147, 1985

58. Howe FA, Filler AG, Bell BA, et al: Magnetic resonance neurography. Magn Reson Med 28:328-338, 1992

59. Hutchison WD, Lozano AM: Microelectrode recordings in movement disorder surgery. Prog Neurol Surg 15:103-117, 2000

60. Jablecki CK, Andary MT, So YT, et al: Literature review of the usefulness of nerve conduction studies and electromyography for the evaluation of patients with carpal tunnel syndrome. AAEM Quality Assurance Committee. Muscle Nerve 16: 1392-1414, 1993

61. Jankovic J, Cardoso F, Grossman RG, et al: Outcome after stereotactic thalamotomy for parkinsonian, essential, and other types of tremor. Neurosurgery 37:680-687, 1995

62. Jasper H: Localized analyses of the function of the human brain by the electroencephalogram. Arch Neurol Psychiatry 36:1131-1134, 1936 (Reference unverified)

63. Jasper H, Bertrand G: Stereotaxic microelectrode studies of single thalamic cells and fibers in patients with dyskinesia. Trans Am Neurol Assoc 89:79-82, 1964

64. Jasper HH: The ten-twenty electrode system of the international federation, in Jasper HH (ed): International Federation of Societies for Electroencephalography and Clinical Neurophysiology: Recommendations for the Practice of 
Clinical Neurophysiology. Amsterdam: Elsevier Scientific, 1983, pp 3-10

65. Josephson BD: Possible new effect in superconductive tunneling. Phys Lett 1:251-253, 1962

66. Katz J: Handbook of Clinical Audiology. Baltimore: Williams \& Wilkins, 1972

67. Kaufman L, Williamson SJ: Magnetic location of cortical activity. Ann N Y Acad Sci 388:197-213, 1982

68. Kellaway P, Crawley JW: A Primer of Electroencephalography of Infants, Sections I \& II: Methodology and Criteria of Normality. Houston: Baylor University College of Medicine, 1964

69. Kellaway P, Mizrahi EM: Neonatal seizures, in Lüders H, Lesser RP (eds): Epilepsy: Electroclinical Syndromes. New York: Springer Verlag, 1987, pp 13-47

70. Kimura J: Electrodiagnosis in Disease of Nerve and Muscle: Principles and Practice, ed 3. New York: Oxford University Press, 2000

71. Knuutila J, Ahlfors S, Ahohen A, et al: Large-area low-noise seven-channel DC SQUID magnetometer for brain research. Rev Sci Instrum 58:2145-2156, 1987

72. Kozelka JW, Pedley TA: Beta and mu rhythms. J Clin Neurophysiol 7:191-207, 1990

73. Krause F: Surgery of the Brain and Spinal Cord, Based on Personal Experiences. New York: Rebman, 1912

74. Laitinen LV, Bergenheim AT, Hariz MI: Leksell's posteroventral pallidotomy in the treatment of Parkinson's disease. J Neurosurg 76:53-61, 1992

75. Legatt AD, Kader A: Topography of the initial cortical component of the median nerve somatosensory evoked potential. Relationship to central sulcus anatomy. J Clin Neurophysiol 17:321-325, 2000

76. Lehman RM, Kim HI: Partial seizures with onset in central area: use of the callosal grid system for localization. Acta Neurochir Suppl 64:79-82, 1995

77. Lehman RM, Mezrich R, Sage J, et al: Peri- and postoperative magnetic resonance imaging localization of pallidotomy. Stereotact Funct Neurosurg 62:61-70, 1994

78. Lenke LG: The clinical utility of intraoperative evoked potential monitoring from a spinal surgeon's perspective. Semin Spine Surg 94:288-294, 1997 (Reference unverified)

79. Liddell EGT, Sherrington CS: Recruitment and some other features of reflex inhibition. Proc R Soc London Biol 96: 212-242, 1924

80. Lieb JP, Engel J Jr, Gevins A, et al: Surface and deep EEG correlates of surgical outcome in temporal lobe epilepsy. Epilepsia 22:515-538, 1981

81. Lozano AM, Hutchison WD, Dostrovsky JO: Microelectrode monitoring of cortical and subcortical structures during stereotactic surgery. Acta Neurochir Suppl 64:30-34, 1995

82. Luders H, Lesser RP, Hahn J, et al: Basal temporal language area demonstrated by electrical stimulation. Neurosurgery 36:505-510, 1986

83. MacDonald DB: Safety of intraoperative transcranial electrical stimulation motor evoked potential monitoring. J Clin Neurophysiol 19:416-429, 2002

84. MacDonald DB, Hirsch BE, Kamerer DB, et al: Acoustic neuroma surgery: predictive criteria for hearing preservation. Otolaryngol Head Neck Surg 104:128, 1991 (Reference unverified)

85. MacGillivray BB (ed): Traditional Methods of Examination in Clinical EEG. Amsterdam: Elsevier Scientific, 1974, Vol 3

86. Maltin CA, Delday MI, Hay SM, et al: Denervation increases clenbuterol sensitivity in muscle from young rats. Muscle Nerve 15:188-192, 1992

87. Markand ON: Alpha rhythms. J Clin Neurophysiol 7: 163-189, 1990

88. Marsan CA, Baldwin M: Electrocorticography, in Baldwin
M, Bailey P (eds): Temporal Lobe Epilepsy. Springfield, IL: Charles C Thomas, 1958, pp 368-398

89. Marsan CA, Zivin LS: Factors related to the occurrence of typical paroxysmal abnormalities in the EEG records of epileptic patients. Epilepsia 11:361-381, 1970

90. Matthies C, Samii M: Management of vestibular schwannomas (acoustic neuromas): the value of neurophysiology for intraoperative monitoring of auditory function in 200 cases. Neurosurgery 40:459-468, 1997

91. Millesi H: Progress in peripheral nerve reconstruction. World J Surg 14:733-747, 1990

92. Moller AR, Jannetta PJ: Monitoring of facial nerve function during removal of acoustic tumor. Am J Otol (Suppl):27-29, 1985

93. Moller AR, Jho HD, Jannetta PJ: Preservation of hearing in operations on acoustic tumors: an alternative to recording brain stem auditory evoked potentials. Neurosurgery 34: 688-693, 1994

94. Monod N, Pajot N, Guidasci S: The neonatal EEG: statistical studies and prognostic value in full-term and pre-term babies. Electroencephalogr Clin Neurophysiol 32:529-544, 1972

95. Nakatoh S, Kitagawa H, Kawaguchi Y, et al: Change of muscle motor-evoked potentials after motor cortex stimulation caused by acute spinal cord injury in cats. J Spinal Disord 14:32-38, 2001

96. Niparko JK, Kileny PR, Kemink JL, et al: Neurophysiologic intraoperative monitoring: II. Facial nerve function. Am J Otol 10:55-61, 1989

97. Novak CB, Mackinnon SE: Patient self reported outcome following anterior transposition of the ulnar nerve. Presented at the Annual American Association of Hand Surgery Meeting. Miami Beach, FL, January 4-6, 2000 (Abstract) (Reference unverified)

98. Novak CB, Mackinnon SE, Patterson GA: Evaluation of patients with thoracic outlet syndrome. J Hand Surg (Am) 18: 292-299, 1993

99. Ochi A, Otsubo H, Chitoku S, et al: Dipole localization for identification of neuronal generators in independent neighboring interictal EEG spike foci. Epilepsia 42:483-490, 2001

100. Ohye C: Depth microelectrode studies, in Schaltenbrand G, Walker AE (eds): Stereotaxy of the Human Brain: Anatomical, Physiological and Clinical Applications. New York: Thieme-Stratton, 1982, pp 372-389

101. Ojemann G, Ojemann J, Lettich E, et al: Cortical language localization in left, dominant hemisphere. An electrical stimulation mapping investigation in 117 patients. J Neurosurg 71:316-326, 1989

102. Ojemann GA: Organization of short-term verbal memory in language areas of human cortex: evidence from electrical stimulation. Brain Lang 5:331-340, 1978

103. Ojemann RG: Strategies to preserve hearing during resection of acoustic neuromas, in Wilkins RH, Rengachary SS (eds): Neurosurgery, ed 2. New York: McGraw-Hill, 1996, Vol I, pp 1095-1099

104. Okada Y: Magnetoencephalography as a noninvasive tool for electrophysiological characterization of auras in classic migraine. Adv Neurol 54:133-140, 1990

105. Owen JH, Kostuik JP, Gornet M, et al: The use of mechanically elicited electromyograms to protect nerve roots during surgery for spinal degeneration. Spine 19:1704-1710, 1994

106. Palmini A, Gambardella A, Andermann F, et al: Intrinsic epileptogenicity of human dysplastic cortex as suggested by corticography and surgical results. Ann Neurol 37:476-487, 1995

107. Papanicolaou AC: Guest editorial: introduction. J Clin Neurophysiol 17:113, 2000

108. Pascual-Leone A, Meador KJ: Is transcranial magnetic stimulation coming of age? J Clin Neurophysiol 15:285-287, 1998 
109. Patton HD, Sundsten JW, Crill WE, et al: Introduction to Basic Neurology. Philadelphia: WB Saunders, 1976

110. Paus T, Jech R, Thompson CJ, et al: Transcranial magnetic stimulation during positron emission tomography: a new method for studying connectivity of the human cerebral cortex. J Neurosci 17:3178-3184, 1997

111. Penfield W, Boldrey E: Somatic and sensory representation in the cerebral cortex of man as studied by electrical stimulation. Brain 60:389-443, 1937

112. Penfield W, Jasper H: Epilepsy and the Functional Anatomy of the Human Brain. Boston: Little Brown, 1954, pp 41-55

113. Penfield W, Roberts L: Speech and Brain-Mechanisms. Princeton: Princeton University Press, 1959

114. Picard C, Olivier A: Sensory cortical tongue representation in man. J Neurosurg 59:781-789, 1983

115. Picton TW: The P300 wave of the human event-related potential. J Clin Neurophysiol 9:456-479, 1992

116. Pollak P, Benabid AL, Gross C, et al: Effects de la stimulation du noyau sous-thalamique dons la maladie de Parkinson. Rev Neurol 149:175-176, 1993

117. Prass RL, Luders H: Acoustic (loudspeaker) facial electromyographic monitoring: Part 1. Evoked electromyographic activity during acoustic neuroma resection. Neurosurgery 19:392-400, 1986

118. Quesney LF, Niedermeyer E: Electrocorticography, in Niedermeyer E, Lopes da Silva F (eds): Electrocorticography: Basic Principles, Clinical Applications and Related Fields, ed 3. Baltimore: Williams \& Wilkins, 1993, pp 695-699

119. Ruch TC, Fulton JF: Medical Physiology and Biophysics, ed 20. Philadelphia: WB Saunders, 1973

120. Samii M, Matthies C: Management of 1000 vestibular schwannomas (acoustic neuromas): the facial nerve-preservation and restitution of function. Neurosurgery 40: 684-695, 1997

121. Sato S, Balish M, Muratore R: Principles of magnetoencephalography. J Clin Neurophysiol 8:144-156, 1991

122. Schaltenbrand G, Bailey P: Introduction to Stereotaxis, With an Atlas of the Human Brain. Stuttgart: Thieme, 1959

123. Schwartz DM: Cranial nerve monitoring, in The Annual Meeting of the American Society of Neurophysiologic Monitoring. St Louis: ASNM, 1996 (Reference unverified)

124. Schwartz DM: Intraoperative neurophysiological monitoring during cervical spine surgery. Oper Techn Orthop 6:6-12, 1996

125. Schwartz DM, Drummond DS, Hahn M, et al: Prevention of positional brachial plexopathy during surgical correction of scoliosis. J Spinal Disord 13:178-182, 2000

126. Schwartz DM, Drummond DS, Schwartz JA, et al: Neurophysiological monitoring during scoliosis surgery: a multimodality approach. Semin Spine Surg 9:97-111, 1997

127. Seddon HJ: Surgical Disorders of the Peripheral Nerves, ed 2. New York: Churchill Livingstone, 1975

128. Silverstein H, Willcox TO Jr, Rosenberg SI, et al: Prediction of facial nerve function following acoustic neuroma resection using intraoperative facial nerve stimulation. Laryngoscope 104:539-544, 1994

129. Smorto MP, Basmajian JV: Clinical Electroneurography: An Introduction to Nerve Conduction Tests. Baltimore: Williams \& Wilkins, 1972

130. Song AW, Popp CA, Mao J, et al: fMRI: methodologyacquisition and processing, in Henry TR, Duncan JS, Berkovic SF (eds): Functional Imaging in the Epilepsies. Philadelphia: Lippincott Williams \& Wilkins, 2000, pp 177-186

131. Spencer S, Bautista ED: Functional neuroimaging in localization of the ictal onset zone, in Henry TR, Duncan JS, Berkovic SF (eds): Functional Imaging in the Epilepsies. Philadelphia: Lippincott, Williams \& Wilkins, 2000, pp 285-296
132. Spencer SS, Guimaraes P, Katz A, et al: Morphological patterns of seizures recorded intracranially. Epilepsia 33: 537-545, 1992

133. Sperling MR, Clancy RR: Ictal EEG, in Engel J Jr, Pedley TA (eds): Epilepsy: A Comprehensive Textbook. Philadelphia: Lippincott-Raven, 1997, pp 849-885

134. Spiegel EA, Wycis HT: Stereoencephalotomy. New York: Grune \& Stratton, 1952

135. Spiegel EA, Wycis HT, Marks M, et al: Stereotaxic apparatus for operations on the human brain. Science 106:349-350, 1947

136. Stefan H, Hummel C, Hopfengartner R, et al: Magnetoencephalography in extratemporal epilepsy. J Clin Neurophysiol 17:190-200, 2000

137. Sunderland S: The anatomy and physiology of nerve injury, in AAEE International Symposium on Peripheral Nerve Regeneration. Washington DC: AAEE, 1989, pp 1-19

138. Sunderland S: Nerves and Nerve Injuries. Baltimore: Williams \& Wilkins, 1968

139. Sutherling WW, Barth DS: Magnetoencephalography in clinical epilepsy studies. The UCLA experience. Adv Neurol 54: 231-245, 1990

140. Taha JM, Favre J, Baumann TK, et al: Tremor control after pallidotomy in patients with Parkinson's disease: correlation with microrecording findings. J Neurosurg 86:642-647, 1997

141. Talairach J, David M, Tournoux P, et al: Atlas d'anatomic Stéréotaxique. Paris: Masson, 1957

142. Tasker RR: Thalamotomy for Parkinson's disease and other types of tremor: Part II: the outcome of thalamotomy for tremor, in Gildenberg PL, Tasker RR (eds): Textbook of Stereotactic and Functional Neurosurgery. New York: McGraw-Hill, 1998, pp 1179-1198

143. Thompson TP, Lunsford LD, Kondziolka D: Technical considerations in movement disorder surgery: frames, imaging and intraoperative monitoring, in Lozano AM (ed): Movement Disorder Surgery. Basel: Karger, 2000, pp 91-102

144. Tillman TW, Olsen WO: Speech audiometry, in Jerger J (ed): Modern Developments in Audiology. New York: Academic Press, 1973, pp 37-74

145. Tobias JV, Elpern BS: The Decibel. Tobias-Elpern, 1964 (Reference unverified)

146. Vieth JB: Magnetoencephalography in the study of stroke (cerebrovascular accident). Adv Neurol 54:261-269, 1990

147. Vitek JL, Bakay RA, Hashimoto T, et al: Microelectrodeguided pallidotomy: technical approach and its application in medically intractable Parkinson's disease. J Neurosurg 88: 1027-1043, 1998

148. Walczak TS, Jayakar P: Interictal EEG, in Engel J Jr, Pedley TA (eds): Epilepsy: A Comprehensive Textbook. Philadelphia: Lippincott-Raven, 1997, Vol II, pp 831-848

149. Walker AE: Cerebral Death, ed 2. Baltimore: Urban \& Schwartzenberg, 1981

150. Wiegand DA, Ojemann RG, Fickel V: Surgical treatment of acoustic neuroma (vestibular schwannoma) in the United States: report from the Acoustic Neuroma Registry. Laryngoscope 106:58-66, 1996

151. Wikswo JP Jr, Friedman RN, Kilroy AW, et al: Preliminary measurements with microsquid, in Williamson SJ, Hohe M, Shornk G, et al (eds): Advances in Biomagnetism. New York: Plenum Press, 1990, pp 681-684

152. Wilbourn AS, Ferrante MA: Clinical electromyography, in Joynt RJ, Griggs RC (eds): Clinical Neurology, ed 2. Philadelphia: Lippincott, Williams \& Wilkins, 1998, Vol 1, pp 49-52

153. Wilbourn AS, Ferrante MA: Clinical electromyography, in Joynt RJ, Griggs RC (eds): Clinical Neurology, ed 2. Philadelphia: Lippincott, Williams \& Wilkins, 1998, Vol 1, pp 61-66

154. Wilbourn AS, Ferrante MA: Clinical electromyography, in 
Joynt RJ, Griggs RC (eds): Clinical Neurology, ed 2. Philadelphia: Lippincott, Williams \& Wilkins, 1998, Vol 1, pp 68-73

155. Woodbury JW, Ruch TC: Muscle, in Ruch TC, Patton HD, Woodbury JW, et al (eds): Neurophysiology. Philadelphia: WB Saunders, 1961, pp 96-127

156. Yalamanchili R, Schwartz DM, Buchheit WA: Intraoperative seventh and eighth nerve and brainstem auditory evoked monitoring. Adv Clin Neurosci 7:17-30, 1997 (Reference unverified)

157. Yingling CD, Gardi JN: Intraoperative monitoring of facial and cochlear nerves during acoustic neuroma surgery. Otolaryngol Clin North Am 25:413-448, 1992
158. Young GB: The EEG in coma. J Clin Neurophysiol 17: 473-485, 2000

Manuscript received July 9, 2003.

Accepted in final form December 15, 2003.

Bladder function and spinal cord injury may be reviewed in the following article: Wein AJ, Rovner ES: Adult Voiding Dysfunction Secondary to Neurologic Disease or Injury. AUA Update Series, Lesson 6, Volume XVIII, American Urological Association, Inc., 1999 Address reprint requests to: Richard M. Lehman, M.D., University of Medicine and Dentistry of New Jersey, Division of Neurosurgery, 125 Paterson Street, Suite 2100, New Brunswick, New Jersey 08901. email: lehmanrm@umdnj.edu. 